El tiempo de las radios no colonizadas

Carlos Barragán

Question/Cuestión, Vol. 2, №66, Agosto 2020

ISSN 1669-6581

https://perio.unlp.edu.ar/ojs/index.php/question/index

IICom-FPyCS-UNLP

\title{
EL TIEMPO DE LAS RADIOS NO COLONIZADAS
}

\section{THE TIME OF NON-COLONIZED}

\section{Carlos Barragán}

Docente de la Facultad de Periodismo y Comunicación Social - UNLP

Periodista, humorista y guionista Conductor de Todos en cuero / FM La Patriada

@carlosbarrgan

\section{Resumen}

Una mirada política sobre la radio en tiempos del macrismo y una reflexión de mediano plazo, para definir la radio que está llegando.

\section{Palabras clave}

Radio, Política, Radios ciudadanas 


\section{Abstract}

A political look at radio in times of macerism and a medium-term reflection, to define the radio that is coming.

\section{Keywords}

Radio, Politics, Citizen radios

\section{Introducción}

\section{La radio: El anclaje vital}

Llegan las fechas redondas y nos acordamos de las cosas. En este caso es la radio que cumple cien años y entonces el momento parece bueno para hacer un arqueo, un recuento de sus luces y sombras, que tratándose de un medio que no se ve tiene su dificultad. Somos quienes hacemos la radio los que generalmente nos ponemos a pensarla, pero quisiera ir aclarando algunas cosas: quienes hacemos radio no somos todos los que usamos un micrófono. Quienes hacemos radio somos los y las que tenemos en la radio un anclaje, una experiencia vital, y no un medio para expresarnos. La radio -para los que hacemos radio- no es un medio, es un cacho de los que somos, y a veces es lo que somos, aunque suene exagerado o un poco enfermizo. Entonces tiene más sentido hablar de la radio desde el amor o la necesidad, las pulsiones que nos unen a ella sin demasiados argumentos intelectuales.

\section{Radio y macrismo}

El pasado gobierno neoliberal fue profundamente enemigo de este medio, como lo fue de tantas cosas que están vivas, y por cuestiones que no vienen al caso me tuvo como uno de los protagonistas -por sustracción- de lo que aquel 
proceso destructivo le quitó a la radio. Me quitó a mí y a muchos más, además de llevar al cierre de varias radios. Pero esto que podría ser motivo de queja prefiero usarlo para entender un poco más sobre ella y sobre nosotros que la hacemos. Porque en medio de la tristeza y los problemas concretos a los que nos condenó el macrismo, recuerdo la alegría cuando me invitaban a una radio. Siempre de esas chiquitas, las cooperativas, las barriales, las populares, y las de los entusiastas que ponen una radio online en el fondo de la casa: las que no tenían nada que perder. La alegría que sentía por tener puestos unos auriculares y un micrófono enfrente es difícil de explicar con argumentos racionales. $Y$ esta irracionalidad no tiene exclusividad, la sentimos muchos. $Y$ así, de pasar a vivir de la radio -como lo hice durante treinta años en los que me fue muy bien- cuando conseguí quien me diera un espacio volví a hacerla gastando de mis ahorros igual que mis compañeros. La radio en los años del macrismo, para muchos de nosotros, fue no sólo una resistencia política, sino y creo que sobre todo- una resistencia moral en el viejo sentido de la palabra: una resistencia del alma. Además de un útero de encuentro con hermanos y hermanas, o compañeros y compañeras (o si prefieren colegas) con quienes compartíamos idénticas vivencias. Quiero decir, además de esfuerzo fue también sanación.

\section{Las enseñanzas de la radio}

Fueron estos cuatro años un gran aprendizaje a todo nivel, pero si hablamos de la radio debo decir que comprendí cuánta fortaleza tienen las cosas livianas que parecen frágiles. Porque cuando los grandes buques de la radiofonía se hundían en el mar de Clarín por la tormenta de Lombardi (y que me disculpe la marinería) las radios hechas con cuatro maderitas fueron los salvavidas de 
muchos y muchas en el naufragio. Y también lo fueron para las audiencias que quedaron huérfanas de lo que querían escuchar. Es interesante ver cómo tenemos mal entendido al capitalismo. Porque contra lo que nos explicaron mil veces, que su objetivo es la mera ganancia monetaria, pudimos comprobar que en principio el capital necesita dominar. No quiere generar riqueza "a cualquier precio", nunca su negocio es la ganancia monetaria basada en la venta de discursos que lo confrontan. Por más que haya muchos consumidores de medios populares, o anti macristas, no van a invertir ahí. El capital primero domina y después hace números. Siempre cuento sobre un economista -la autorreferencia me la disculparán o no- que nos decía en 2015 en los últimos días de 678 que el programa iba a seguir porque teníamos mucho público, y que donde hay un público siempre hay empresas interesadas en venderle algo. Pero no es así, a ninguna empresa le interesa financiar o ser auspiciante de una comunicación que convoca ideas emancipadoras y de mínima antimonopólicas. Y si algún empresario confundido quisiera quebrar esta lógica, de inmediato aparecerá la concentración mediática para hacerle entender que si quiere vender su mercadería apoyando el discurso incorrecto no tendrá lugar para publicitar en los medios grandes. Y si no entiende, los medios grandes y el capital concentrado que son dedos de una misma mano, tienen maneras más rigurosas para hacerse entender.

\section{Las vueltas a la radio}

Como un tipo de radio me crie en una FM muy exitosa. No hice el camino esperado de empezar en un medio barrial hasta llegar a "la cima radiofónica". Lo mío fue una rareza, una casualidad o el destino, si es que no son lo mismo: de la nada empecé a trabajar con Lalo Mir que era primero en su horario en 
una radio que era primera inter pares. Eran los 90, libre mercado a rabiar, privatizaciones y lavandinas y lavandas por doquier, pesos que parecían dólares, y las radios eran parte de ese banquete fantástico que era acompañado por audiencias masivas reales. Viví aquellos tiempos con una felicidad irrepetible, por la radio que me hizo saber quién era y para qué era. No por el menemismo que fue siempre una invitación a la inacción y la apatía, y para muchos un obligado tobogán hacia la simple miseria. Cuento esto porque este camino inverso, desde una radio FM exitosa en los 90 hasta una radio popular y cooperativa, pobre y chiquita, pasando por alguna AM importante y por la radio estatal, me tiene siempre sorprendido. Sorprendido por ser testigo y protagonista de cómo la política, el poder, la economía y los medios dan resultados imprevisibles. Porque durante los peores años nacieron unas y crecieron otras radios, todas ellas a contracorriente. Como si las metáforas musculares, que con los esfuerzos cotidianos las cosas se fortalecen, fuesen casi una literalidad.

Hoy sabemos de las dificultades de nuestro gobierno con la comunicación opositora y la propia. La comunicación de la oposición, que ya dejó de ser aquel brazo del poder concentrado que se encargaba de la aplicación de las operaciones políticas, para ser directamente la cabeza política que toma decisiones estratégicas y las aplica desde sus medios. La otra dificultad es con la comunicación propia, la que emana de los medios estatales, que vista desde afuera parece estar definida por la decisión de no repetir la política confrontativa del kirchnerismo con el objetivo de evitar mayores perturbaciones. La dificultad que esto conlleva es que la "confrontatividad" es una calidad definida por los medios opositores, con lo cual para evitarla no queda mucho más que volverse mudo. Sin embargo, cuando miramos encuestas de opinión 
no podríamos asegurar que la apuesta del gobierno fracasó, porque allí -en líneas generales- encontramos una alta aprobación a la actual gestión. Cabe la pregunta de cómo evitar que los medios dominantes abandonen sus ataques sistemáticos y su dinámica destituyente. $\mathrm{Y}$ la respuesta es que no hay nada que hacer. Para eso existen y para eso son el poder concentrado en la búsqueda permanente de fortalecer sus privilegios para lo cual necesitan deteriorar la democracia, los derechos de los ciudadanos y el igualitarismo.

\section{El tiempo de las radios no colonizadas}

Por eso creo que es el gran momento de los medios populares, y específicamente en lo que nos toca: las radios comunitarias. En ellas no hacen pie los cálculos y las roscas de la política real, la profesionalizada, la que se encuentra atada a las necesidades herejes, como los son todas las necesidades. Por eso podemos desde estos medios seguir construyendo ciudadanía con las manos libres. Estas radios donde cada día más audiencias acuden para ser parte de una comunicación que las contiene y las representa porque por su propia índole son los medios menos mediatizados, menos colonizados por la lógica del rating, el marketing y otras disciplinas habladas en inglés. La radio quizá -no quisiera pecar de optimista, pero tampoco creo que el pesimismo sea garantía de inteligencia- está pasando por un momento de renovación y fortalecimiento. Novedades, rejuvenecimiento y potencias desde sus estudios precarios que las grandes radios de la dominancia comunicacional no están contrarrestando, con sus audiencias de jubilados en estado de shock, y sus programaciones que envejecen a fuerza de repetición y consignas machacadas. Estos cuatro años pasados dejaron las huellas y son la prueba de que no es tan sencillo clausurar las voces no domesticadas por el poder. Ahora 
le toca al futuro contarnos el resto de nuestra historia. $Y$ ya sabemos que el futuro no viene, somos nosotros los que vamos hacia él y lo amasamos todos los días. 